\title{
Publisher Correction: Notch1 regulates the initiation of metastasis and self-renewal of Group 3 medulloblastoma
}

\author{
Suzana A. Kahn 1,2,3,4, Xin Wang (10 5, Ryan T. Nitta ${ }^{3}$, Sharareh Gholamin 1,2,3, Johanna Theruvath',

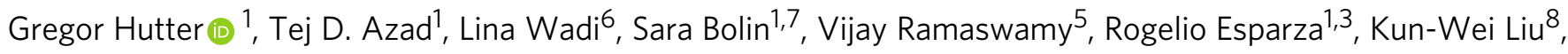 \\ Michael Edwards (i) ${ }^{3,4}$, Fredrik J. Swartling7 ${ }^{7}$ Debashis Sahoo9, Gordon Li ${ }^{3}$, Robert J. Wechsler-Reya ${ }^{8}$, \\ Jüri Reimand ${ }^{6,10}$, Yoon-Jae Cho ${ }^{4}$, Michael D. Taylor ${ }^{5}$, Irving L. Weissman (D) ${ }^{2,4}$, Siddhartha S. Mitra (1D ${ }^{1,2,3,4,11}$ \& \\ Samuel H. Cheshier $1,2,3,4,12$
}

Correction to: Nature Communications https://doi.org/10.1038/s41467-018-06564-9; published online 08 October 2018

The original version of this Article omitted Suzana A. Kahn, Siddhartha S. Mitra \& Samuel H. Cheshier as jointly supervising authors. This has now been corrected in both the PDF and HTML versions of the Article.

Published online: 02 November 2018

(i) Open Access This article is licensed under a Creative Commons Attribution 4.0 International License, which permits use, sharing, adaptation, distribution and reproduction in any medium or format, as long as you give appropriate credit to the original author(s) and the source, provide a link to the Creative Commons license, and indicate if changes were made. The images or other third party material in this article are included in the article's Creative Commons license, unless indicated otherwise in a credit line to the material. If material is not included in the article's Creative Commons license and your intended use is not permitted by statutory regulation or exceeds the permitted use, you will need to obtain permission directly from the copyright holder. To view a copy of this license, visit http://creativecommons.org/licenses/by/4.0/.

(C) The Author(s) 2018

\footnotetext{
${ }^{1}$ Division of Pediatric Neurosurgery, Lucile Packard Children's Hospital, Stanford University School of Medicine, Stanford 94305 California, USA. ${ }^{2}$ Institute for Stem Cell Biology and Regenerative Medicine and the Ludwig Cancer Center, Stanford University School of Medicine, Stanford 94305 California, USA. ${ }^{3}$ Department of Neurosurgery, Stanford University School of Medicine, Stanford 94305 California, USA. ${ }^{4}$ Ludwig Institute for Cancer Research, Stanford University School of Medicine, Stanford 94305 California, USA. 5 Division of Neurosurgery, Arthur and Sonia Labatt Brain Tumor Research Centre, Hospital for Sick Children, University of Toronto, Toronto M5G OA4 Ontario, Canada. ${ }^{6}$ Computational Biology Program, Ontario Institute for Cancer Research, Toronto M5G OA3 Ontario, Canada. ${ }^{7}$ Department of Immunology, Genetics and Pathology, Science for Life Laboratory, Rudbeck Laboratory, Uppsala University, Uppsala 75185, Sweden. ${ }^{8}$ Tumor Initiation and Maintenance Program, Sanford Burnham Prebys Medical Discovery Institute, 2880 Torrey Pines Scenic Drive, La Jolla 92037 California, USA. ${ }^{9}$ Department of Pediatrics and Department of Computer Science and Engineering, University of California San Diego, San Diego 92093 California, USA. ${ }^{10}$ Department of Medical Biophysics, University of Toronto, Toronto M5G $1 \mathrm{L7}$ Ontario, Canada. ${ }^{11}$ Department of Pediatrics, Children's Hospital Colorado, University of Colorado, School of Medicine, Room No. P18-4114, Research Complex 1-North MS-8302, 12800 East 19th Avenue, Aurora, Colorado 80045, USA. ${ }^{12}$ Division of Pediatric Neurosurgery, Department of Neurosurgery, Primary Children's Hospital and Huntsman Cancer Institute, University of Utah, 100 North Mario Capecchi Drive Suite 3850, Salt Lake City, Utah 84113, USA. These authors contributed equally: Suzana A. Kahn, Siddhartha S. Mitra \& Samuel H. Cheshier. Correspondence and requests for materials should be addressed to S.A.K. (email: suzanakahn@gmail.com) or to S.H.C. (email: samuel.cheshier@hsc.utah.edu)
} 